\title{
A Revista de Antropologia \\ e as ciências sociais em São Paulo: notas sobre uma cena e alguns debates
}

\author{
Fernanda Arês Peixoto \\ Professora do D epartamento de Antropologia-USP \\ Júlio Assis Simões \\ Professor do D epartamento de Antropologia-U SP
}

RESU M 0 : 0 artigo busca situar o contexto intelectual da criação e dos primeiros dez anos de existência da Revista de Antropologia, em que ganha destaque a emergente produção universitária de ciências sociais, no interior de um movimento de delimitação e especialização de áreas e setores do conhecimento. A partir da releitura de artigos, resenhas e comentários ali publicados - tendo em comum o questionamento das possibilidades da investigação antropológica das "sociedades complexas" - , delineou-se um mapa das questões relacionadas à "mudança cultural", então em voga, no qual ressaltam tanto a colaboração entre sociólogos e antropólogos como os embates entre e dentro de cada disciplina, em seu(s) respectivo(s) nicho(s) institucional(ais). A análise esboçada aponta a importância de qualificar a polarização, tão freqüentemente real çada, entre disciplinas e instituições universitárias nas ciências sociais em São Paulo nesse período.

PALAVRAS-CH AVES: Revista de Antropologia, ciências sociais no Brasil, estudos de comunidade, mudança cultural. 
F. A. Peixoto e J. A. Simões. A Revista de Antropologia e as ciências socials...

Este artigo, menos que um balanço da Revista de Antropologia ou apanhado de sua história, reúne notas que foram sendo alinhavadas (a quatro mãos) a partir da releitura dos primeiros números da publicação. Trata-se, antes de mais nada, de ol har para a Revista no momento de sua criação e em seus primeiros anos de existência, pensando-a como lugar de observação de uma cena de época e de al guns debates que aí tiveram lugar. C ena e debates, vale lembrar, nos quais ela foi protagonista.

A apresentação escrita por Egon Schaden ${ }^{1}$ para o primeiro número da Revista de Antropologia da Faculdade de Ciências e Letras da U SP, de junho de 1953, destaca a importância da nova publicação diante da "falta de revistas especializadas". A afirmação, longe de protocolar, obriga a consideração de um cenário específico, cujo timbre é dado pela especialização do trabalho intelectual em curso e pelo processo de autonomização dos campos artístico e científico. Se os decênios de 1920 e 1930 "ficarão em nossa história intelectual como de harmoniosa convivência e troca de serviços entre literatura e estudos sociais", como quer Antonio C andido, as décadas posteriores, de 1940 e 1950, assistem ao progressivo afastamento desses campos do conhecimento, quando, não por acaso, vem à tona a primeira fornada de estudos universitários.

A longa proeminência da literatura em nossa vida intelectual - "fenômeno central da vida do espírito" entre nós, indica Candido - fez da sociologia, durante largo período, mais "ponto de vista" do que pesquisa sistemática da realidade, o que se revela no fértil cruzamento entre ciência e arte, marcante em nossa tradição ensaística (C andido, 1967, p. 157). As universidades criadas na década de 1930, como sabido, jogam papel destacado na definição das distintas esferas do saber, imprimindo novos formatos à produção intelectual. As grandes sínteses de interpretação do país tendem, a partir de então, a ceder lugar aos recortes específicos, às pesquisas sistemáticas sobre novos objetos, com o au- 
Revista de Antropologia, São Paulo, U SP, 2003, v. 46 no 2.

xílio de metodologias particulares, exaustivamente apresentadas nas introduções das monografias científicas².

0 mercado editorial constitui um bom termômetro para localizarmos as feições de uma época, os anos 1950, nos quais se observam esforços de delimitação de áreas e setores do conhecimento. Seisso éverdade, as primeiras publicações especial izadas - algumas delas, disciplinares - convivem com periódicos de perfil mais eclético. Em todos eles, cabe notar, se fazem presentes as primeiras gerações universitárias, seja pela apresentação de resultados de pesquisas e/ou pelo comentário crítico de livros.

D esde 1935, por exemplo, a Revista do Arquivo M unicipal - ligada ao D epartamento de Cultura de São Paulo, dirigida e secretariada por M ário de Andrade e Sérgio M illiet, respectivamente - acompanha as pesquisas levadas a cabo na Escola de Sociologia e Política (ESP), contando ainda com a colaboração sistemática dos professores da Faculdade de Ciências e Letras da U SP3. Esses professores, estrangeiros em sua maioria, estão ligados à Sociedade de Etnografia e Folclore e à Sociedade de Sociologia (Rubino, 1995), participando também da D ivisão de D ocumentação Social eEstatística, criadas por M ário no interior do D epartamento de Cultura.

Alguns anos mais tarde, outra revista cultural, Anhembi, criada e dirigida por Paulo Duarte em 1950, vai acompanhar de perto a efervescência artística do período, abrigando, entre outros, a nova produção universitária, como revelam as colaborações regulares de Roger Bastide, Florestan Fernandes, O racy N ogueira, entre outros (Pereira, 1987)4. Brasiliense (1955-1964), embora mais afeita ao debate políticoideológico, aproxima-se de Anhembi ao seguir detidamente o mundo cultural paulista. Aí também se fazem presentes os cientistas sociais da U SP, sobretudo as novas gerações ligadas à cadeira de Sociologia I, como Fernando H enriqueC ardoso, $\mathrm{O}$ ctavio Ianni eoutros (Limongi, 1987a). 
F. A. Peixoto e J. A. Simões. A Revista de Antropologia e as ciências socials...

Se a produção universitária, sociológica e antropológica, é absorvida pelas publicações culturais em circulação em São Paulo desde meados da década de 1930, não tardarão a surgir veículos especializados na divulgação das pesquisas realizadas na Faculdade de Ciências e Letras da U SP e na Escola de Sociologia e Política. Sociologia, criada em 1939, por Emilio W illems e Romano Barreto, aparece como um primeiro esforço nessa direção. Seu ano de criação coincide com o momento em que as escolas de ensino superior formam as primeiras turmas, o que indica o vínculo direto da revista com a produção universitária. Tal vínculo irá assumir feição institucional um pouco mais tarde quando, a partir do terceiro volume, a revista se torna órgão da ESP.

Sociologia, indica o título, volta-se para uma área específica do conhecimento, e tem como objetivo ser uma "Revista D idática e Científica", destinada aos interessados na matéria. Até 0 ano de 1948, aponta Limongi, o caráter didático se sobrepõe ao científico, o que irá se alterar na segunda fase da publicação, de 1949 a 1957, quando O racy N ogueira assume a direção do periódico, com a colaboração de Emilio W illems, D onald Pierson eM auro Lopes. Aí, passa a se apresentar como "Revista dedicada à teoria e pesquisa em Ciências Sociais" (Limongi, 1987b). É importante lembrar que a criação de uma seção de estudos pós-graduados na ESP, nos anos de 1940, e os doutoramentos concedidos pela U SP, a partir de 1945, constituem iniciativas fundamentais para a definição de especializações e de especial istas, o que reverbera no perfil das publicações a partir desse momento.

A criação de uma Revista de Antropologia em São Paulo, em 1953, acompanha um movimento mais amplo de definições disciplinares a ecoar nas publicações criadas ao longo da década, e que se relaciona de perto à construção de instituições de diferentes tipos no período ${ }^{5}$. Lembremos, em São Paulo, de H abitat, revista dirigida por Lina Bo Bardi a partir de 1950, e associada ao M ASP recém-criado, preferencialmente 
voltada para arquitetura e urbanismo; ou do Suplemento Literário de 0 Estado de S. Paulo (1956), interessado na produção literária nacional einternacional e estreitamente ligado à U niversidade de São Paulo, desde seu diretor, D écio de Almeida Prado ${ }^{6}$. No que diz respeito à antropologia especificamente, não é possível deixar de mencionar a Revista do M useu Paulista, cuja nova série iniciada em 1947, sob o comando de $\mathrm{H}$ erbert Baldus, salienta seu perfil antropológico ${ }^{7}$.

Se os antropólogos se fazem presentes nas diversas publicações em circulação nos anos de 1940 e 1950, tomando lugar de destaque em várias delas ${ }^{8}$, a criação de um véculo especialmente dedicado à matéria tem efeitos importantes sobre a configuração das ciências sociais em São Paulo. Ainda que, desdea criação da Universidade de São Paulo, a Sociologia possua proeminência no currículo da FCL, com duas cadeiras (Sociologia I ell) ao lado de uma de Antropologia e uma de Ciência Política, será a Antropologia aquela a conceber um veículo próprio, que se tornará órgão da faculdade e depois do D epartamento de Ciências Sociais ${ }^{10}$. Lembremos ainda que a Revista virá a ser órgão oficial da Associação Brasileira de Antropologia (ABA), em 1956, e da Sociedade Brasileira de Sociologia (SBS), a partir de 1958, o que indica suas ramificações para fora da faculdade e de São Paulo.

Ser, ao mesmo tempo, veículo do D epartamento de Ciências Sociais e das duas associações nacionais, de Antropologia e Sociologia, parece dizer al go sobre o perfil da publicação em seus primeiros anos, e sobre as feições que toma uma parte da produção antropológica paulista, sobretudo aquela voltada para as chamadas "sociedades complexas": sua estreita ligação com a sociologia. A leitura dos 20 primeiros números da publicação (1953-1972) confirma essa imbricação entre sociologia e antropologia em parte significativa da antropologia produzida em São Paulo, e que pode ser aferida pelas colaborações regulares de sociólogos da U SP e da ESP, assim como pela forte presença dos estudos de comu- 
F. A. Peixoto e J. A. Simões. A Revista de Antropologia e as ciências socials...

nidade e das pesquisas sobre contato e assimilação, que articulam de perto as perspectivas antropológica e sociológica. N esse sentido, a publicação fornece um mapa das questões em voga no momento - as questões de mudança cultural, por exemplo - que mobilizaram sociólogos e antropólogos a pesquisar no $\mathrm{campo}^{11}$, nas comunidades e na cidade. Além disso, convida-nos a nuançar dicotomias continuamente repostas nas avaliações sobre a produção sociológica em São Paulo, por exemplo a que coloca U SP e ESP em cantos opostos do ringue, em termos de formação teórico-metodológica e de produção intelectual. D iferenças à parte, o fato é que as duas instituições foram mais parceiras que oponentes, colaborando na formação de pesquisadores (Emilio W illems foi professor nas duas escolas), trocando alunos (lembremos que Florestan Fernandes e Gioconda M ussolini, entre muitos outros, passaram pela seção de estudos pós-graduados da ESP), participando de projetos comuns e das mesmas revistas. 0 que não poderia ser de outro modo, dadas as dimensões reduzidas do meio intelectual à época, que fazem da proximidade fato incontornável.

0 exame mais detido do desenvolvimento de alguns debates do período - e que a Revista apresenta - nos conduz a relativizar ainda as distâncias teóricas entre USP e ESP. N ão se trata de negar as diferenças entre feitios institucionais e orientações metodológicas, como dito, mas de pensar, com base na leitura da revista, como há um repertório de questões e preocupações partilhado por todos aqueles envolvidos com a pesquisa antropológica e sociológica em São Paulo nos anos de 1950. $O$ Ihemos mais de perto para al gumas delas.

$$
* * *
$$

Análises recentes sobre o desenvolvimento da antropologia no Brasil apontam que, dos anos 1930 aos 1960, a especialização crescente da 
disciplina, bem como a definição da identidade profissional do antropólogo no âmbito das ciências sociais decorrem da ênfase nos assuntos indígenas, tanto na pesquisa como na preocupação política (C orrêa, 1988). Apesar disso, Eunice D urham, ao traçar um apanhado sucinto da trajetória da disciplina no mesmo período, afirma que "o grande impulso da antropologia nessa época está muito mais relacionado ao estudo da sociedade nacional do que ao das culturas indígenas" (D urham, 1982). M esmo se referida preponderantemente ao contexto de institucionalização da disciplina em São Paulo, essa observação chama a atenção para a centralidade da preocupação com temas brasileiros e com o estudo da sociedade brasileira em seu conjunto na pesquisa, na reflexão teórica e no debate político de que participam os acadêmicos brasileiros à época.

Se tomarmos como referência os artigos publicados nos dez primeiros anos de existência da Revista de Antropologia, de 1953 a 1963, notaremos que os autores brasileiros aí presentes dedicam-se, na maioria, a temas brasileiros - a sociedade rural tradicional, a imigração estrangei$\mathrm{ra}$, as formas de associação na cidade, entre outros - , ou ainda, a questões teóricas e metodológicas decorrentes dessas pesquisas sobre integração e mudança da sociedade nacional, como os "estudos de comunidade" e de "aculturação". Enquanto isso, os autores estrangeiros, que até então respondiam por mais da metade dos artigos publicados e entre os quais encontramos um considerável número de alemães -, são os que se ocupam principalmente das sociedades e culturas indígenas $^{12}$. M esmo os poucos brasileiros, que comparecem com páginas dedicadas a assuntos indígenas - como Eduardo $G$ al vão e Roberto $C$ ardoso de 0 liveira, além do próprio Egon Schaden -, tendem a abordálos da perspectiva de sua inserção e envolvimento na sociedade ou na cultura nacional ${ }^{13}$. 
F. A. Peixoto e J. A. Simões. A Revista de Antropologia e as ciências socials...

Essa espécie de divisão de trabal ho, entre nacionais e estrangeiros, ea predominância numérica destes últimos nos primeiros anos da Revista de Antropologia associam-se a características marcantes da institucionalização das ciências sociais no Brasil e da própria produção antropológica da época, apontadas por vários comentadores; tais como a precariedade geral da formação oferecida em etnologia nas instituições acadêmicas da época, o treinamento ainda incipiente na pesquisa de campo, o interesse primordial dos antropólogos dos países centrais pelo estudo de sociedades e culturas não-européias. Sem pretender dar conta de todo esse panorama, gostaríamos de chamar a atenção para dois aspectos, mais especificamente relacionados com os rumos em curso no contexto paulista de institucional ização da antropologia.

Em primeiro lugar, é preciso sublinhar o contraste de concepções da disciplina que parece embutido nesse quadro e que a publicação permite flagrar. $N$ ão há como desconhecer a marca da formação pessoal e dos interesses de pesquisa de Egon Schaden - segundo professor a ocupar a Cátedra de Antropologia da U SP, de 1949 a 1967 - , nos primeiros anos de existência da Revista da Antropologia. A ênfase em etnologia indígena - e na etnografia guarani, em particular - vem acompanhada do interesse por antropologia física, arqueologia, genética e lingüística, em conformidade com uma concepção de antropologia como "a compreensão científica da natureza humana", num sentido bastante amplo e diversificado, que Schaden já explicitara, no primeiro artigo que publicara na Revista ${ }^{14}$, e que parecia esposar. Já a produção sobre temas brasileiros aponta, em contrapartida, uma visão da disciplina mais aproximada do formato paulista das "ciências sociais": uma antropologia em estreita colaboração com a sociologia, na qual os pesquisadores não só compartilhavam temas e orientações teóricas, mas também "se deslocavam freqüentemente de uma disciplina para a outra" (D urham, 1982). 
Revista de Antropologia, São Paulo, U SP, 2003, v. 46 № 2.

0 segundo aspecto a destacar é que essas concepções não são apenas distintas, mas se apresentam como concorrentes, nos dois sentidos do termo: convergem e competem nas mais importantes instituições acadêmicas paulistas no período. $\mathrm{N}$ a perspectiva da colaboração estreita entre antropologia e sociologia, os estudos de comunidade, introduzidos sob influência de antropólogos e sociólogos norte-americanos, formam uma linha de pesquisa emblemática da produção da década de 1950. Fundamentados na observação direta de pequenas localidades ou vilas, por meio de técnicas de pesquisa forjadas no estudo das então chamadas "sociedades tribais", deram ensejo a uma série de pesquisas monográficas cobrindo grande parte das regiões do país, com as quais se pretendia chegar a uma visão de conjunto da sociedade brasileira ${ }^{15}$. Em prosseguimento aos estudos de mudança cultural iniciados nos anos 1930, os de comunidade se concentram nas características da sociedade rural tradicional em transformação. Embora marca institucional da Escola de Sociologia e Política, esses estudos guardam afinidades e continuidades com a perspectiva representada por Schaden na U SP em muitas de suas preocupações conceituais e metodológicas, como indica 0 foco na temática da "aculturação"16.

Além disso, vale lembrar que as preocupações com questões de mudança cultural, observada a partir do impacto da modernização (leia-se, urbanização) sobre sociedades e culturas tradicionais - caras aos estudos de comunidade - , dão o tom de parte significativa da produção da época, seja na ESP, seja na U SP. Lembremos o estudo de Antonio C andido sobre os parceiros do Rio Bonito (tese defendida em 1954) e as pesquisas de Florestan Fernandes sobre o folclore na década de 1940, que exemplificam claramente 0 compromisso com essa pauta, enfrentada com 0 auxílio de um repertório bibliográfico semelhante. A despeito das afinidades evidentes, os pesquisadores da USP fazem questão de marcar uma distância em relação aos estudos de comunidade. 0 prefá- 
F. A. Peixoto e J. A. Simões. A Revista de Antropologia e as ciências socials...

cio de Antonio Candido ao livro Os parceiros do Rio Bonito, publicado em 1964, é esclarecedor:

Abordam-se aqui problemas que vêm sendo, em nosso país, estudados através da estatística, ou da monografia de comunidade. Essa tese não é uma coisa, nem outra (...) não é um "estudo de comunidade", no sentido hoje corrente, sobretudo entre americanos e ingleses. $\mathrm{N}$ ão pretendi levantar sistematicamente os diferentes aspectos de determinado agrupamento, englobando todo o seu sistema institucional numa visão completa e orgânica. D epois de bastante hesitar, rejeitei esse ponto de vista, em parte pelo que tem de estático e convencional - levando-nos quase sempre a encarar os traços de uma dada realidade sociocultural como algo que, para usar velha expressão caipira, "deverá ser assim mesmo". Por outras palavras, 0 estudo de comunidade, em seu corte descritivo mais freqüente, me pareceu comprometer no pesquisador o senso de problemas. (C andido, 1979, p. 19-20)

É da USP justamente que provêm muitas das objeções teóricas e metodológicas aos "estudos de comunidade" e, por extensão, aos estudos de "aculturação". Parte significativa dessa discussão aparece em artigos e resenhas publicados nos primeiros dez anos da Revi sta de Antropologia. Julgamos estar aqui um caminho privilegiado para avaliar o debate em torno dos rumos da teoria e da pesquisa, bem como para qualificar o movimento teórico de crítica a uma certa orientação "culturalista", cuja influência é reconhecida na trajetória imediatamente posterior da antropologia no Brasi ${ }^{17}$. $\mathrm{Na}$ Cátedra de Antropologia da USP, essa influência já se fazia presente no trabalho de pesquisa e orientação desempenhado por sua mais antiga assistente, Gioconda M ussolini ${ }^{18}$. Vale lembrar que a crítica à orientação "cultural ista" dos trabal hos está referida a embates institucionais, acadêmicos e políticos ligados à institucionali- 
Revista de Antropologia, São Paulo, U SP, 2003, v. 46 № 2.

zação, bem-sucedida, da cadeira de Sociologia I na U SP. N ão é à toa queela aparece freqüentementeem termos deuma (falsa) oposição entre antropologia e sociologia, oposição esta que reverbera inclusive dentro da própria sociologia, cindida em duas cadeiras: a primeira voltada às questões relativas à "sociedade" e a segunda encarregada do quinhão menos "nobre", da "cultura".

0 único artigo que Gioconda publica na Revista de Antropologia, no período em questão ("Aspectos da cultura e da vida social do litoral brasileiro"), embora não referido diretamente aos "estudos de comunida$\mathrm{de}^{\prime 19}$, apresenta al guns dos pontos teóricos e conceituais recorrentes na avaliação crítica destes. A proposta do artigo, de construir generalizações com vistas a caracterizar o litoral como um universo de análise, apresenta-se como um esforço de avançar na compreensão de situações particulares mediante a abstração de fatores gerais, que poderiam ser tratados como estruturas sociais - no caso, buscadas em aspectos da cultura material e na organização do trabalho da pesca, como fundamentos da atividade comunitária e do senso de identidade coletiva. D iz ela: "é na pesca ao redor da rede que se estabelece toda uma série de interações entre os moradores de um bairro, unindo-os em cooperação, e fazendo com que constituam, realmente, um grupo local"20. A trama de relações comunitárias é considerada em seu entrosamento num conjunto maior, o que faz com que ela se altere por influência de fatores cuja ação se exerce a distância, e que a atraem para a órbita de outros centros. É o que teria ocorrido no litoral paulista, com a progressiva organização da pesca em moldes capitalistas, que abriu caminho para a mobilidade social, a quebra da organização dos grupos locais ea "perda dos elementos de sua cultura de folk".

0 artigo de Gioconda M ussolini parece uma tentativa de combinar os ganhos e a relevância do estudo sincrônico de relações funcionais ou de traços culturais - próprios da abordagem dos "estudos de comuni- 
F. A. Peixoto e J. A. Simões. A Revista de Antropologia e as ciências socials...

dade" - com um esforço de análise diacrônica da cultura e das relações sociais. Ela insinua uma "terceira alternativa" em face da polarização do debate em torno das contribuições científicas e práticas dos "estudos de comunidade" - polarização bem exemplificada por dois comentários críticos publicados na Revista sobre 0 assunto: 0 de 0 racy N ogueira e 0 de 0 ctavio Ianni' ${ }^{21}$.

O racy, ainda na Escola de Sociologia e Política, defende a importância dos "estudos de comunidade" como "verdadeiro movimento intelectual, o mais vigoroso até o momento, na história da pesquisa sociológica no País". D entre suas contribuições teóricas, destaca o seu papel de complemento e corretivo em relação aos estudos analíticos, por meio da interpretação de dados referidos a uma mesma localidade, "isentos quer da interpolação de dados reais extralocais, quer do preenchimento de lacunas do material via conjeturas". 0 rigor e a precisão na delimitação espacial, na observação e no tratamento descritivo, vistos por N ogueira como grande virtude dos "estudos de comunidade, tornam-se para Ianni - então um dos mais proeminentes discípulos de Florestan Fernandes uma camisa-deforça imposta ao pesquisador, privando-o da "riqueza e desenvoltura no uso criador da inteligência", que marcavam a tradição ensaística anterior. É interessante observar que N ogueira e Ianni levantam e examinam aspectos semelhantes, no que se refere à concentração em dados singulares, em detrimento de fatores gerais, aos problemas de representatividade na seleção das comunidades para estudo e às finalidades práticas das pesqui sas. Chegam, porém, a conclusões opostas: para O racy N ogueira, os "estudos de comunidade", com sua atenção voltada à teia de relações contidas numa localidade bem determinada, constituiriam um método de coleta e interpretação compatível com as mais variadas perspectivas teóricas, permitindo colocar, sob outro ângulo, hipóteses surgidas e desenvolvidas por meio de estudos feitos sob outras orientações ${ }^{22}$. Para 0 ctavio Ianni, por sua vez, é precisamente por vol- 
Revista de Antropologia, São Paulo, U SP, 2003, v. 46 № 2.

tar-se para a investigação intensiva, microscópica e local izada que a pesquisa falha em realizar a "explanação completa": "estudos de comunidade são solução metodológica confundida com modelo teórico de compreensão da realidade". I anni evoca a formulação de Conrad Arensberg - da "comunidade" como unidade de observação para o estudo da cultura e da sociedade, ou como expressão local de um fenômeno ou problema social geral - para afirmar que os estudos de comunidade desenvolvidos no Brasil não foram capazes de explorar as possi bilidades abertas pelos melhores exemplos congêneres norte-americanos. $N$ os estudos nacionais, a comunidade deixou de ser unidade de observação para se converter em objeto em si, suscetível de propiciar por si só um conhecimento significativo. Isso retiraria dos "estudos de comunidade" toda legitimidade científica. Em suma, procedimentos que $\mathrm{O}$ racy N ogueira via como mutuamente complementares, Ianni considerava mutuamente exclusivos.

Em resenhas publicadas, um pouco mais tarde, por Eunice $D$ urham e Ruth C ardoso - então auxiliares de Gioconda M ussolini -, podemos encontrar pistas do que viria ser apresentada como uma orientação alternativa à polaridade posta nas discussões acerca dos estudos de comunidade. $\mathrm{N}$ a resenha relativa à segunda edição da coletânea $\mathrm{C}$ aribbean Studies, D urham também retoma a discussão de Conrad Arensberg e 0 modo como este salienta que o método de estudo de comunidade é de "obtenção de dados, e não de análise". Frisa que os dados assim obtidos são "indispensáveis para a compreen são da cultura", mas logo acrescenta que "não são os únicos necessários, especialmente no caso de comunidades que se integram numa sociedade complexa"23. Segundo a leitura de D urham, essas observações inspiradas em Arensberg não invalidam os estudos de comunidade como empreendimento científico, mas sublinham sua importância, desde que redirecionados ao estudo dos processos de mudança social e cultural. Essas idéias reaparecem na resenha 
F. A. Peixoto e J. A. Simões. A Revista de Antropologia e as ciências socials...

de Eunice D urham sobre o livro de G eorge Foster, Traditional cultures and the impact of technological change $e^{24}$, famoso ensaio de "antropologia aplicada". A autora chama a atenção para o modo como Foster apresenta uma reavaliação da relevância dos estudos de comunidade, tanto "do ponto de vista científico" como "do ponto de vista imediato da ação", ao conferir importância às zonas urbanas como foco de mudança e às conseqüências amplas da integração de comunidades relativamente isoladas numa economia de mercado.

N essa mesma resenha, são destacadas as limitações de se focalizar a mudança cultural do ponto de vista dos agentes sociais diretamente envolvidos, ou da perspectiva dos mecanismos locais de controle social idéia que a autora retoma em outras ocasiões, a pretexto de comentários críticos de outros trabal hos. D urham, leitora de Foster, assinal a que as comunidades não são auto-suficientes, e sim sujeitas a influências e diretivas que não podem controlar. N essa medida, não se pode considerar que suas populações sejam livres para tomar decisões, "pois a mudança depende de fatores alheios ao seu controle". D e outra parte, 0 foco nas instituições locais "fornece apenas uma visão estática e parcial do processo dinâmico mais amplo em que as mudanças se inserem". Assim, não seria possível explicar a mudança cultural independentemente da análise das características da sociedade mais ampla, de seu desenvolvimento socioeconômico, da organização de sua burocracia governamental, e assim por diante.

U ma síntese da concepção e do papel da antropologia, sob essa mesma perspectiva, é oferecida por D urham em nova resenha (sobre o livro de Richard Adams, A community in the Andes. Problems and progress in M uquinayo) ${ }^{25}$. Diz ela:

o que se pode pretender através da investigação antropológica não é certamente a reconstituição completa deuma realidade histórica particular, mas 
Revista de Antropologia, São Paulo, U SP, 2003, v. 46 № 2.

ao contrário, no nível da abstração que nos permite tratar de estruturas, chegar-se, através da análise, a determinar fatores gerais, que seriam fundamentais para um determinado resultado.

A mesma ênfase em mudança cultural, urbanização, processos sociais e especificidade das "sociedades complexas" comparece em resenhas assinadas por Ruth Cardoso, cujo alvo privilegiado é a questão da "aculturação". N o comentário sobre o famoso livro de Julian Steward, Theory of culture change ${ }^{26}$, então recém-lançado, Cardoso saúda a proposta de um novo método de análise que possibilita combinar o foco em regularidades sincrônicas, como padrões e relações causais que se repetem em diferentes culturas, e o interesse por dinâmica e mudança cultural27. A concepção de "níveis de integração sociocultural", proposta por Steward, é ressaltada como uma contribuição importante para tratar de aspectos de mudança cultural que se passam junto a "subgrupos" ou "subculturas" diferencialmente atingidos pelas causas da mudança. C ardoso vê a proposta de Steward como uma alternativa à visão clássica da cultura como configuração total, especialmente proveitosa para estudos antropológicos em "sociedades contemporâneas complexas", que exigiriam "novos instrumentos de trabalhos, capazes de apreender esta nova real idade, que já não apresenta mais a homogeneidade das culturas tribais". E completa:

Q uanto ao processo de aculturação, uma das maiores preocupações da antropologia contemporânea, poderá ser melhor compreendido se procurarmos reconhecer quais os subgrupos culturais mais atingidos e se a mudança opera num nível familial, comunitário ou racional.

$\mathrm{N}$ a resenha do livro de Altiva Pilatti Balhana, Santa Felicidade: um processo de assimilação ${ }^{28}$ - uma pesquisa sobre aculturação de uma po- 
F. A. Peixoto e J. A. Simões. A Revista de Antropologia e as ciências socials...

pulação de italianos próxima a Curitiba, no formato de "estudo de comunidade" - , Ruth Cardoso ressalta, por sua vez, o cuidado ea minúcia da descrição etnográfica, ao mesmo tempo em que lamenta a ausência de análises e interpretações que expliquem as transformações, as redefinições e o funcionamento de padrões culturais antigos e novos na localidade focalizada:

Temos aí uma descrição minuciosa da vida das famílias, de suas atividades rotineiras, seus êxitos, seus trabalhos e das inovações que paulatinamente as vão atingindo. 0 que fal ta é a tentativa de explicar o processo de assimilação, de esclarecer como funcionam os padrões culturais europeuse como são abandonados ou modificados.

U m breve cotejo dos artigos escritos por Egon Schaden e por Ruth C ardoso, sobre a aculturação dos imigrantes al emães ejaponeses no Brasil ${ }^{29}$, oferece um exemplo da "fricção intertextos" (C orrêa, 1995) encontrada nas páginas da Revista de Antropologia em seus primeiros anos. Comparando as situações de imigrantes alemães e japoneses, Schaden observa, com base em dados de W illems, que os alemães estabeleceram combinações culturais várias, como soluções transitórias, junto à sociedade brasileira, de modo a configurar uma "cultura teuto-brasileira". Já os japoneses, segundo Schaden, não encarariam a possi bilidade de uma "solução de compromisso": ou se apegam à cultura tradicional ou a renegam de maneira cabal. Essa atitude seria característica, respectivamente, das duas gerações sucessivas de imigrantes: os mais jovens abandonam a colônia eas atividades da lavoura, integram-seà sociedade local por meio da competência em atividades técnicas ou comerciais, enela competem com elementos que não são de sua etnia. U ma importante implicação disso seria a ruptura e a desorganização familial na colônia japonesa. 
Ruth Cardoso, ao relatar e analisar diversos percursos de mobilidade social entre imigrantes japoneses, chama a atenção para "dois aspectos aparentemente contraditórios de uma mesma ideologia" que atuariam simultaneamente para produzir uma situação peculiar na colônia japonesa: de um lado, a valorização aberta e franca da vida rural; de outro, a valorização do estudo ea preocupação com a instrução dos filhos. Cardoso procura compreender como essa dual idade opera no desenvolvimento do "contato entre brasileiros e japoneses" e "quais as mudanças tacitamente admitidas nos padrões japoneses" para al cançar seus objetivos. A análise mostra assim padrões de negociação entre as diferentes gerações na família, nos quais os mais velhos aceitam mudanças na organização coletiva tradicional do trabalho doméstico quando estas dizem respeito aos filhos escolhidos para serem transformados em pessoas de destaque. 0 s mais jovens, por seu turno, mantêm uma dupla leal dade. São membros da colônia e devem ter prestígio aos olhos desta, mas esse prestígio aumenta à medida que os jovens ultrapassam seus limites e se afirmam como profissionais liberais bem-sucedidos dentro da sociedade mais ampla - e, para tanto, têm de se comportar como "brasileiros".

Em contraste com a análise de Schaden, configuram-se aqui as "soluções de compromisso", mesmo em face de situações nas quais os mais jovens radicalizam seu processo de "abrasileiramento". Segundo C ardoso, a distância crescente, decorrente desses casos, não aumenta o conflito familiar, na medida em que a percepção do sucesso dos mais jovens, por parte dos mais velhos, segue contribuindo para a aceitação das inovações. D esse modo, a autora ressalta que, ao se focalizar o processo de mudança cultural e integração cultural, é possível mostrar como valores tidos como "núcleos do conservadorismo" podem assumir novas funções, dadas as condições específicas do contato, e não impedem a emergência de objetivos paralelos. 
F. A. Peixoto e J. A. Simões. A Revista de Antropologia e as ciências socials...

O s "estudos de comunidade" e os problemas de aculturação parecem ter sido, assim, reavaliados por meio de esforços de sistematização, voltados a identificar fatores constantes que, mais do que preservar formas estabelecidas de integração, promoveriam uma reorganização de componentes socioculturais para fazer frente à mudança. $\mathrm{No}$ artigo de $\mathrm{M} \mathrm{a}$ ria Sylvia de $\mathrm{C}$ arvalho Franco M oreira ${ }^{30}$, pode-se encontrar uma elaboração de propostas teóricas e metodológicas afinadas com as idéias que temos levantado até aqui. Franco M oreira considera que o foco em situações de coexistência de elementos de estabilização e mudança faz dos "estudos de comunidade" uma via estratégica para a compreensão das relações entre condições socioculturais e econômicas, sendo estas tratadas não só como "poderoso fator de determinação de condiç̧̃es sociais", mas também "produto de sua capacidade criadora". Para que isso se torne efetivo, porém, é necessário "sair da modalidade clássica de realização desses estudos". A preocupação com uma delimitação espacial precisa da comunidade deveria ser posta de lado, desde que não se trate de descrever e explicar exaustivamente unidades locais per se, mas "desvendar mecanismos de integração dos componentes estruturais e funcionais relevantes para os propósitos da pesquisa", o que implica incorporar à análise e à interpretação fenômenos ocorridos fora da área estritamente delimitada, desde que "inscritos em situações históricas de mesmo tipo". Acrescenta a autora, citando um artigo de Gioconda M ussolini ${ }^{31}$, a necessidade de completar a pesquisa de campo com a pesquisa histórica, importante para que se reconheçam "modalidades diversas de organização do sistema mais amplo, do qual as comunidades fazem parte". Critica também a forma de utilização dos conceitos que definem as "relações comunitárias" de parentesco, vizinhança e ajuda mútua, que enfatizam sentimentos de identidade e vontade coletiva e tendem a "excluir toda idéia de oposição e luta, estratificação e domínio". 0 foco da 
análise deveria se dirigir para as relações societárias, nas quais se acreditava que proviriam os "elementos criadores" 32 .

Os balanços e comentários críticos realizados sobre os "estudos de comunidade" - elaborados de formas diferentes e a partir de lugares distintos - parecem bater numa mesma tecla: 0 risco do encapsulamento da comunidade pela desconsideração de seus vínculos com a sociedade mais ampla e com a história ${ }^{33}$. $\mathrm{N}$ ão se trata aqui de negar a pertinência das objeções brevemente arroladas, mas de chamar a atenção para dois aspectos. Em primeiro lugar, para a importância da consideração dos embates teóricos, mas também institucionais e políticos, que têm lugar na época para a compreensão do tom - muitas vezes exal tado - de parte das críticas feitas, que parece converter os "estudos de comunidade" numa espécie de "categoria de acusação". Em segundo, para o momento em questão, marcado por tentativas de definição de uma "antropologia das sociedades complexas" - que os textos de Cardoso e D urham exemplificam -, que não se confunda com sociologia nem com "estudos de comunidades", embora dialogue com ambos. Cabe lembrar ainda que um dos principais desenvolvimentos acadêmicos e institucionais imediatos, ligados a esse debate, foi o desenvolvimento de linhas de pesquisa em antropologia urbana, com ênfase nas relações entre cultura e política, sob orientação de Eunice D urham e Ruth C ardoso, nos anos 1970 e 1980, num contexto político geral bastante distinto, tanto no País quanto na universidade.

A leitura da Revista de Antropologia em seus anos iniciais permite 0 rastreamento de diferentes trilhas temáticas, teóricas e metodológicas, pelo acompanhamento de pistas que vão sendo oferecidas a cada número: nos artigos, nas resenhas, nos informativos. Privilegiamos aqui algu- 
F. A. Peixoto e J. A. Simões. A Revista de Antropologia e as ciências socials...

mas delas, sem a pretensão de esgotá-las, com o intuito apenas delevantar questões.

As formulações brevemente examinadas sobre al gumas das linhas de tensão e debate, num período crucial da institucionalização das ciências sociais em São Paulo, tiveram como propósito auxiliar no esboço de um retrato mais nuançado não só da formação da disciplina em São Paulo, como dito no início, mas da própria publicação. D iferentes orientações convivem na Cátedra de Antropologia da USP, de modo nem sempre apaziguado. 0 stextos permitem aferir distintas concepções da disciplina, bem como o processo de constituição de subdisciplinas. Se, de um lado, é patente que, nos primeiros 20 volumes da publicação, a maior parte das colaborações referia-se à etnologia ${ }^{34}$, ficam claros também os esforços para a constituição de uma "antropologia das sociedades complexas", que, como procuramos mostrar, têm de se haver com a grande influência exercida pela perspectiva histórico-estrutural erigida na Cátedra de Sociologia I sobre todos os pesquisadores que se dedicam à antropologia mesmo entre aqueles que nem sempre se identificavam como antropólogos - e com os estudos de comunidade, realizados preferencialmente na Escola de Sociologia e Política. Os embates presentes nas páginas da Revista nos dão uma idéia do esforço de "organização de um consenso", jamais atingido plenamente, para a eventual hegemonia exercida pela cadeira de Sociologia I junto aos cientistas sociais paulistas ${ }^{35}$.

Acreditamos que estes e outros temas relevantes, para a compreensão dos rumos da pesquisa e da discussão teórica em antropologia e da institucionalização das ciências sociais entre nós, podem receber contribuições inovadoras com base num olhar sistemático sobre a produção contida na Revista de Antropologia - tentativa que aqui apenas esboçamos, como convite a futuros interessados. 
Revista de Antropologia, São Paulo, U SP, 2003, v. 46 № 2.

\section{N otas}

1 Egon Schaden foi o principal idealizador da Revista de Antropologia e diretor da publicação entre 1953 e 1972.

2 Vale lembrar que, do lado das artes e da literatura, por sua vez, a decantação dos campos se refleteno incremento das tendências formal istas que têm lugar no período. Afinal, livre da tarefa de servir de acesso ao conhecimento da realidade, o artista pode desenvolver a pesquisa propriamente estética. Para o caso específico da poesia, cf. Camilo (2001).

3 A relação das publicações dos professores da ESP, de 1933 a 1942, indica como a Revista do Arquivo M unicipal éum vé́culo privilegiado de divulgação das pesquisas universitárias. Publicam regularmente no periódico: Samuel H. Lowrie, H orace D. Davis, Herbert Baldus, D onald Pierson, Emilio Willems, entre outros. Cf. Kantor, M aciel \& Simões (2001, p. 182-90).

4 A presença da produção sociológica universitária na publicação pode ser aferida pela edição seriada de Relaçães raciais entre negros e brancos em São Paulo (X-XI, 1953), resultado da pesquisa patrocinada pela U N ESCO e dirigida em São Paulo por Roger Bastide e Florestan Fernandes.

5 M aria Arminda do N. Arruda (2001) assinala o vigor institucional que toma a cidade de São Paulo ao longo dos anos 1940 e 1950. Lembra, entre outros, a criação de museus de arte, como o M ASP (1947) e o M AM (1949), a Escola de Arte D ramática, o Teatro B rasileiro de Comédia (1948) ea Companhia C inematográfica Vera Cruz (1949).

6 Podemos indicar ainda a título de exemplo, já que não se trata de desenhar um quadro nacional, a Revista Brasileira de Estudos Políticos (RBEP), editada em M inas G erais a partir de 1956, eo Boletim do Instituto Joaquim N abuco de Pesquisa Social (mais tarde, Ciência e Trópico), que vem a público em 1952, no Recife.

7 Luiz Jackson (2003) chama a atenção para o papel da Revista do M useu Paulista como precursora da edição na íntegra de trabalhos universitários, suprindo a lacuna deixada pelo mercado editorial da época, com a edição de A moda no sé́ulo XIX, de Gilda de M ello eSouza, em 1951; de Função social da guerra na sociedade Tupinambá, de Florestan Fernandes, em 1952; de 0s Caraybas negros, de Ruy Coelho, em 1964; e de Bai rros rurais paulistas, de M aria Isaura Pereira de Q ueiroz, em 1967. 
F. A. Peixoto e J. A. Simões. A Revista de Antropologia e as ciências socials...

8 Lembra Limongi (1987b), como, na primeira e segunda fases (1939-1957) de Soci ologia, os estudos etnológicos ocupam lugar destacado, 0 que se deve à participação de H erbert Baldus.

9 A Cátedra de Antropologia na U SP foi instituída em 1941, sendo Emilio W illems o seu primeiro ocupante. Egon Schaden substituiu Willems "a título precário", em 1949, tendo sido seu concurso de cátedra realizado somente em 1965. João Baptista Borges Pereira sucedeu Schaden em 1967. H avia ainda na U SP uma cátedra mais antiga, de Etnografia Brasileira e Língua Tupi-Guarani, regida desde 1935 pelo engenheiro Plínio Ayrosa, e extinta em 1962. D urante mais de 20 anos as duas cátedras existiram lado a lado, aparentemente sem maiores contatos entre si. Em 1970, o sistema de cátedras foi extinto e substituído pelo de departamentos. Cf. Corrêa (1995).

10 Luiz Jackson (2003) defende a tese de que a estratégia da cadeira de Sociologia I e de Florestan Fernandes inverte as trilhas comumente seguidas pelos grupos. Ao invés de lançar seu próprio veículo, Florestan se faz presente em todas as revistas, utilizando-as, segundo ele, como "caixas de ressonância" para a legitimação de seu projeto acadêmico.

11 Luiz Jackson (2003) chama a atenção para a forte presença dos estudos rurais na publicação.

12 Essas informações se baseiam em José Augusto Laranjeiras Sampaio, "Revista de Antropologia (vols. 1 a 20): um índice e algumas notas", mimeo, s/d.; e Paula M ontero, "Apresentação", Revista de Antropologia, vol. 36, 1993.

13 Sem esquecer os estudos sobre parentesco terena etukuna, publicados por Roberto C ardoso de O liveira, eque podem ser colocados entre os primeiros trabalhos brasileiros a discutir os modelos de Lévi-Strauss. Cf. Roberto $\mathrm{C}$ ardoso de O liveira, "M atrimônio e solidariedade tribal terena: uma tentativa de análise estrutural", Revista deAntropologia, vol. 7, n. 1 e2, 1959; idem, "Aliança interclânica na sociedade tukuna", Revista de Antropologia, vol. 9, n. 1 e 2, 1961.

14 Egon Schaden, "Problemas do ensino de Antropologia", Revista de Antropologia, vol. 2, n. 1, 1954.

150 trabalho deEmilio W illems, U ma vila brasileira (2.ed., São Paulo, Difel, 1961), é considerado o primeiro estudo de comunidade feito no Brasil, nos anos 1940. Júlio C ezar M elatti (1986-1990) cita duas dezenas de estudos desse tipo, publicados ao longo das décadas de 1950 e 1960. 
Revista de Antropologia, São Paulo, U SP, 2003, v. 46 № 2.

16 D entre os vários trabalhos de Schaden, ver "Aculturação indígena: ensaio sobre fatores e tendên cias da mudança cultural de tribos índias em contato com o mundo dos brancos", sua tese de cátedra publicada como o volume 13 da Revista de Antropologia, em 1965.

17 A crítica ao "culturalismo" ganha força a partir dos estudos de contato interétnico de Roberto Cardoso de O liveira, de grande importância tanto do ponto de vista da inflexão teórica quanto de suas conseqüências institucionais. Cardoso de Oliveira tem papel destacado na constituição da moderna pós-graduação em antropologia no Brasil, a partir de sua atuação no M useu N acional. Seu projeto de pesquisa "Preliminares de uma pesquisa sobre a assimilação dos Terena" foi publicado na Revista de Antropologia (vol. 5, n. 2, 1957). Para um análise da influência da sociologia de Florestan Fernandes no trabalho teórico e institucional de R oberto Cardoso de O liveira, ver Corrêa (1995).

18 Gioconda M ussolini estava vinculada à C átedra de Antropologia desde 1943, fez seu mestrado na ESP, sob orientação de Baldus em 1944. Sem ter concluído 0 doutorado à época da aposentadoria de Egon Shaden, não pôde concorrer à sua sucessão. Faleceu em 1969.

19 Lembremos que Gioconda M ussolini escreveu em co-autoria com Emilio W illems um estudo sobre uma comunidade caiçara na ilha de Búzios.

20 Gioconda M ussolini, "Aspectos da cultura e da vida social do litoral brasileiro", Revista de Antropologia, vol. 1, n. 2, 1953.

210 artigo de 0 racy N ogueira é "O s estudos de comunidade no Brasil", Revista de Antropologia, vol. 3, n. 2, 1955. Essa comunicação havia sido apresentada na I Reunião Brasileira de Antropologia, ocorrida no Rio de Janeiro, em dezembro de 1953. 0 artigo de 0 ctavio Ianni é "Estudo de comunidade e conhecimento científico", Revista deAntropologia, vol. 9, n. 1 e 2, 1961.

22 Nogueira refere-se em nota às críticas feitas por Caio Prado Jr. ao trabalho de W illems sobre Cunha, observando que elas atingem "o trabalho em si" e não "0 método empregado". 0 alvo explícito dos ataques de lanni também é o trabalho deW illems. D e certo modo, os dois artigos evocam al gumas das posições em confronto esgrimidas, respectivamente, por Emilio W illems ("Velhos e novos rumos no estudo das classes sociais") e por Florestan Fernandes ("A análise sociológica das classes sociais") no "Symposium sobre classes sociais", publicado no volumeX da revista Sociologia, em 1948. U ma análise desse debate pode ser encontrada em Corrêa (1995). 
F. A. Peixoto e J. A. Simões. A Revista de Antropologia e as ciências socials...

23 Resenha publicada na Revista de Antropologia, vol. 9, n. 1 e 2, 1961.

24 Resenha publicada na Revista de Antropologia, vol. 11, n. 1 e 2, 1963.

25 Resenha publicada na Revista de Antropologia, vol. 10, n.1 e 2, 1962.

26 Resenha publicada na Revista de Antropologia, vol. 6, n. 2, 1958.

27 É interessante notar a afinidade entre a ênfase posta em cultura material, por Gioconda M ussolini no artigo referido acima, e a idéia de Steward de "núcleo da cultura", como padrões relacionados às atividades de subsistência. É também oportuno lembrar que Steward é a inspiração da crítica à perspectiva da aculturação feita por Eduardo Galvão, em comunicação apresentada na I Reunião Brasileira de Antropologia e publicada como "Estudos sobre a aculturação de grupos indígenas no Brasil", na Revista de Antropologia, vol. 5, n. 1, 1957.

28 Resenha publicada na Revista de Antropologia, vol. 9, n. 1 e 2, 1961.

290 artigo de Schaden é "Aculturação de alemães e japoneses no Brasil", Revista de Antropologia, vol. 4, n. 1, 1956. 0 de Ruth Cardoso é "O agricultor eo profissional liberal entre os japoneses no Brasil", Revista de Antropologia, vol. 11, n. 1 e 2, 1963. Em depoimento a M ariza Corrêa, Ruth Cardoso lembra que "no momento em quefiz minha pesquisa com os japoneses, todo meu empenho era em organizar um material com que eu pudesse contestar a idéia de aculturação" (C orrêa, 1995).

30 M aria Sylvia de Carvalho Franco M oreira, "O estudo sociológico de comunidades", Revista de Antropologia, vol. 11, n. 1 e 2, 1963.

310 artigo de Gioconda M ussolini citado por M aria Sylvia C. Franco M oreira é "Persistência e mudança em sociedades de folk no Brasil", Anais do XXXI Congres so Internacional de Americanistas, vol. I, São Paulo, Anhembi, 1955.

32 Essa crítica parece se voltar mesmo contra os colegas antropólogos. A preocupação em marcar fronteirasé clara a partir do uso de "sociológico" no título do artigo.

33 Além dos artigos publicados na Revista deAntropologia aqui mencionados, cf. também Woortmann (1972).

34 Cf. o artigo de M ariza Corrêa publicado neste mesmo número, "Revista de Antropologia: 1953-2003. U ma revista para muitas histórias".

35 Para um aprofundamento dessa história, cf. os volumes, organizados por Sérgio M iceli (1989 e 1995), H istória das ciências sociais no Brasil. 
Revista de Antropologia, São Paulo, U SP, 2003, v. 46 № 2.

\section{Bibliografia}

ARRUDA, M. A. do N .

2001 M etrópole ecultura, Bauru, EDUSC.

CAM ILO, V.

2001 D rummond, da rosa do povo à rosa as trevas, São Paulo, Ateliê.

CANDIDO, A.

1967

"Literatura e cultura de 1900 a 1945", in Literatura e sociedade, 2.ed., São PauIo, Cia. Editora Nacional.

1979 Os parceiros do Rio Bonito, 5.ed., São Paulo, D uas Cidades.

CORRÊA, M.

1988

"Traficantes do excêntrico: os antropólogos no Brasil dos anos 30 aos anos 60", Revista Brasileira de Ciências Sociais, n. 6: p. 79-98.

1995 "A Antropologia no Brasil (1960-1980)", in M ICELI, S. (org.), H istória das ciências sociais no Brasil, vol. 2, São Paulo, Sumaré/Fapesp, p. 25-106.

DURHAM , E. R.

1982

"O s problemas atuais da pesquisa antropológica no Brasil", Revista de Antropologia, vol. 25.

JACKSON, L. C.

2003 "Sociologianas revistas", XXVII Encontro Nacional da Anpocs, GT Pensamento Social no Brasil, Caxambu.

KANTOR, I.; M ACIEL, D.; SIM ÕES, J. (org.)

2001 A Escola Livre de Sociologia e Política, anos deformação - D epoimentos, São PauIo, Fapesp/Escuta.

LIMONGI, F. P.

1987a “M arxismo, nacionalismo e cultura: Caio Prado J r. ea Revista Brasiliense”, Re vista Brasileira de Ciências Sociais, n. 5, vol. 2.

1987b Revista Sociologia. A ELSP e o desenvolvimento da sociologia em São Paulo, São Paulo, IDESP, Série H istória das Ciências Sociais, n. 1. 
F. A. Peixoto e J. A. Simões. A Revista de Antropologia e as ciências sociais...

MELATTI, J. C.

1986-1990 "A Antropologia no Brasil: um roteiro", in 0 que se deve ler em Ciências Sociais no Brasil, vol. 3, São Paulo, Cortez/Anpocs.

MICELI, S. (org.)

1989

H istớia das ciências sociais no Brasil, 1930-1960, vol. 1, São Paulo, Idesp/ Fapesp.

1995 H istớia das ciências sociais no Brasil, vol. 2, São Paulo, Idesp/Fapesp.

PEREIRA, M . de S. F.

1987 Anhembi: criação e perfil de uma revista de cultura, São Paulo, Idesp, Série H istória das Ciências Sociais, n. 2.

RUBINO, S.

1995

"Clubes de pesquisadores. A Sociedade de Etnografia e Folclore ea Sociedade de Sociologia", in MICELI, S. (org.) H istớia das ciências sociais no Brasil, vol. 2, São Paulo, I desp/Fapesp.

WOORTMAN N, K.

1972 "A antropologia brasileira e os estudos de comunidade", U niversitas, Salvador, n. 11. 
ABST RACT: This article discusses the intellectual context pertaining to the period of the founding and first decade of existence of the Revista de Antropologia. Attention is given to the growing importance of university-based production in the social sciences at the time, as areas of specialization and sectors of knowledge are defined. A reexamination of articles, book reviews and commentaries - which are seen to reflect a general interest in exploring possibilities of the anthropological investigation of "complex societies" allows for an effort to outline a set of questions relating to "cultural change", one of the major themes of the period. This study presents clear evidence of collaborative efforts involving sociologists and anthropologists, as well as of disputes within and between their respective disciplines and institutional niches. Ideas pertaining to the so-called polarized relations, so often emphasized, involving university disciplines and institutions in the social sciences of São Paulo during this period, can be fruitfully reconsidered on the basis of the material here presented.

KEY-W ORDS: Revista de Antropologia, social sciences in Brazil, community studies, cultural change. 